\section{DEVLIN NAMED}

\section{DISTINGUISHED SCIENTIST}

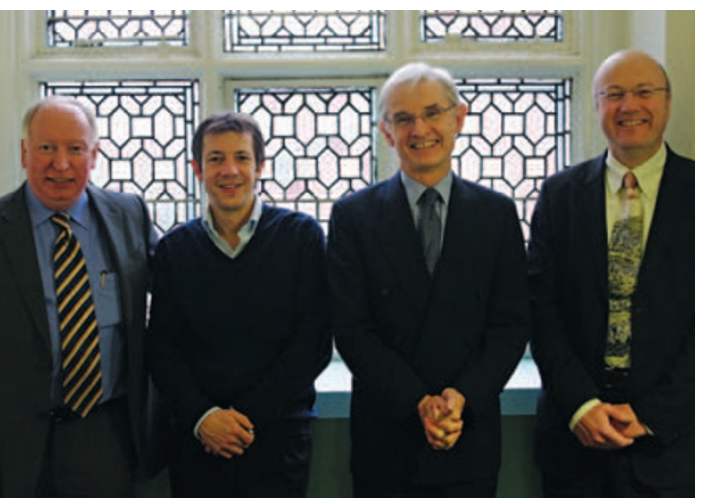

Professor Hugh Devlin from the University of Manchester has received the Distinguished Scientist Award for research in prosthodontics and implants from the International Association for Dental Research (IADR).

Professor Devlin joins a highly distinguished group of professors from the University of Manchester who have previously received this award. Pictured from left to right are Professor David Watts (2003), Professor Michael Dixon (2001), Professor Hugh Devlin (2011) and Professor Mark Ferguson (2000).

Professor Mackie, Head of the School of Dentistry, said that he was delighted with Professor Devlin's award as it highlighted Manchester's continuing excellence in research.

\section{GDC CHAIR RESIGNS}

Alison Lockyer, Chair of the General Dental Council (GDC), has resigned with immediate effect.

In a statement issued on 6 May announcing her resignation as both Chair and as a member of the GDC, Dr Lockyer said 'It would not be appropriate at the moment for me to go into detail about my reasons for resigning, suffice to say that, over the last few months, there have been issues that have caused me concern.' She continued, 'I remain passionate about the importance of protecting the public through professional self regulation.'

Dr Lockyer was elected GDC Chair in December 2009 and took office on 1 January 2010.

\title{
BDA APPEALS TO PROFESSION ON RED TAPE CHALLENGE
}

The British Dental Association (BDA) is calling on the profession to join in the government's 'Red Tape Challenge' by drawing attention to the myriad rules and regulations that distract them from providing patient care.

The BDA welcomes this initiative, which government ministers say not only offers the public an opportunity to say what they really think of unnecessary regulation, but also commits them to repealing legislation that cannot be justified.

In a new pledge to get rid of unnecessary red tape, government departments will have to justify every single set of the 21,000 statutory rules and regulations in force today. Taxation, national security and EU laws are the only areas exempt from this scrutiny which will take place over the next two years. The exercise will apply to legislation in Northern Ireland, Scotland and Wales, where the government has jurisdiction.

The BDA has also warned that government plans for dental public health do not go far enough. While supporting both the broad approach of the plans and some of the specific proposals in the government's Healthy lives, healthy people white paper, the BDA would like to see a more ambitious approach to dental public health. It is also concerned that a shortage of consultants in dental public health may affect the availability of appropriate expertise.

The BDA would like to see a target set for improving the oral health of older patients; action taken to tackle oral health inequalities; and a stronger approach to reducing sugar intake both for oral health and to tackle obesity.

'There are gaps in the proposals where we think the Government should be going further,' said Dr Susie Sanderson, Chair of the BDA's Executive Board. 'We'd like to see a more ambitious vision for dental public health that seeks to guarantee the availability of the staff and financial resources that are needed to improve oral health.'

\section{PALEOZOIC REPTILES HAD TOOTHACHE TOO}

A study ${ }^{1}$ has revealed an infection in the jaw of a 275-million-year-old terrestrial reptile, highlighting the high cost of having permanent teeth.

According to Robert Reisz and his colleagues from the University of Toronto, our susceptibility to oral infection has some parallels to those of ancient reptiles that evolved to eat a diet incorporating plants in addition to meat. The research team found evidence of bone damage due to oral infection in Paleozoic reptiles as they adapted to living on land.

The researchers discovered the bone destruction with the aid of CT-scanning while investigating the jaws of several well-preserved specimens of Labidosaurus hamatus.

As the ancestors of advanced reptiles diversified to life on land, many evolved dental specialisations to feed more efficiently on other animals and to incorporate high-fibre plant leaves and stems into their diet. The primitive dental pattern in which teeth were loosely attached to the jaws and continuously replaced changed to be strongly attached to the jaw, with little or no tooth replacement. This allowed them to chew their food and thus improve nutrient absorption. However, Reisz's team suggest that as this reptile lost the ability to replace teeth, the likelihood of infections of the jaw, resulting from damage to the teeth, increased substantially. This is because prolonged exposure of the dental pulp cavity of heavily worn or damaged teeth to oral bacteria was much greater than in other animals that quickly replaced their teeth.

'Our findings allow us to speculate that our own human system of having two sets of teeth is more susceptible to infection than that of our distant ancestors that had a continuous cycle of tooth replacement,' concluded the authors.

1. Reisz R R, Scott D M, Pynn B R, Modesto S P. Osteomyelitis in a Paleozoic reptile: ancient evidence for bacterial infection and its evolutionary significance. Naturwissenschafen 2011; DOI: 10.1007/s00114-011-0792-1. 